Journal of Teacher Education for Sustainability, vol. 21, no. 1, pp. 103-114, 2019

\title{
Textbooks as Resources for Education for Sustainable Development: A Content Analysis
}

\author{
Zhila Mohammadnia and Farzane Deliery Moghadam \\ Urmia University, Urmia, Iran
}

\begin{abstract}
If we intend to successfully integrate Education for Sustainable Development (ESD) in the general educational programs, it is important to utilize available methods and resources. This paper argues that English Language Learning textbooks in Iran have the potential to be useful resources and a viable springboard for the implementation of ESD. For this purpose, the present study explores the content of English textbook series developed by Iranian authors through the lenses of ESD. The framework for analysis was based on UNESCO's Earth Charter and the Roadmap for Implementing the Global Action Program on ESD. The findings reveal that the themes of sustainability are present in these English textbooks to a good extent. However, the results suggest that there must be a more even distribution of such themes throughout the series. Also, the role of the teacher as a facilitator in developing discussions around such themes is highlighted.
\end{abstract}

Keywords: Education for Sustainable Development, EFL, ESL, textbook, content analysis, resource.

\section{Introduction}

Sustainability, as an unavoidable step for human beings toward living in harmony with the natural environment, has been emphasized in recent decades. In line with the international efforts for establishing sustainability as an essential concept in human societies, the UN named a decade, from 2005 to 2014, the United Nations Decade of Education for Sustainable Development. Although educating people about this theme may not be enough to ensure a more peaceful and harmonious life with nature, it initiates an awareness raising agenda that can be influential in integrating such ideas with the existing thought systems among different peoples. Rieckmann (2018, p. 39) outlines the scope of Education for Sustainable Development as:

Education for Sustainable Development (ESD) aims to develop competencies that enable and empower individuals to reflect on their own actions by taking into account their current and future social, cultural, economic and environmental impacts from both a local and a global perspective. 
Education has a transformative function and can be the site for creating a culture of sustainability (Cutanda \& Murga-Menoyo, 2014). UNESCO has pinpointed the important role education plays in bringing about change in societies:

Only education and learning at all levels and in all social contexts can bring about this critical change. Education is a fundamental lever of change contributing to poverty eradication, sustainable development, equity, and inclusiveness. It is also a means of realizing broader social, economic, political and cultural benefits. It empowers all people of all ages with the knowledge, skills, and confidence they need to shape a better future. (UNESCO, 2012, p. 13).

When considering a fundamental change in the belief system and education of any country, it becomes obvious that this change requires a great deal of work in various fields. This might include areas such as teacher training, curriculum development, and of course material development among others. Although this transformation needs to take place in general education, its importance can be even more evident in language classrooms. Since language cannot be separated from culture, the people who learn a language are exposed to the culture of that language. As McDervitt (2004) puts it, cultural literacy even to some extent is necessary when learning a language. Therefore, considering the position of English as an international language in the world, the concerns for sustainability must have a place in English classes. English can be the proper medium to introduce and discuss the principles of sustainability. Therefore, it can pave the way for changes in the thoughts and beliefs of learners.

The sources for an EFL/ ESL (English as a Foreign Language, English as a Second Language) class vary in different contexts with regard to the characteristics of the learners, learning contexts, teachers and language school management. However, the most commonly used sources are the textbooks. As Hutchinson and Torres (1994, p. 323) put it "The textbook can be not just a learning program for language content, but also a vehicle for teacher and learner training". The content of communicative textbooks usually covers various topics in different sections such as passages, conversations, listening exercises, and even grammar exercises. By taking a look at available textbooks, one can see that they enjoy a wide variety of topics such as social norms of behaving in different contexts and cultures, social and environmental issues, art, technology, fables, health, and animals to name a few. The content of English textbooks thus can be analyzed to see if they are compatible with sustainability themes and if not modified. In the present paper, we take the stance that English textbooks have the potential to spread the culture of sustainable life and by means of content evaluation of an English textbook series, we aim to contribute to improving educational resources that English learners use in their journey of learning a language. For this purpose, the content of a series of textbooks widely used in Iran will be analyzed to see if they contain the principles of sustainability stated in two documents: The UNESCO Roadmap for Implementing the Global Action Program on ESD and the Earth Charter. According to this roadmap, the main areas of sustainable development include climate change, biodiversity, disaster risk reduction, and sustainable consumption and production (UNESCO, 2014, p. 11). The Earth Charter was published in 2000 by the United Nations Educational Scientific and Cultural Organization (UNESCO) and is recognized as "a benchmark of an educational model for sustainable development” (Cutanda \& Murga-Menoyo, 2014, p. 19). 


\section{Literature Review}

Two lines of research were related to the present study. One was the studies which focused on the analysis of textbooks in some way and the other was the projects which had sustainability as their main focus.

Textbooks have not attracted much attention from researchers in terms of content analysis. However, a review of the existing literature can reveal that some discourse oriented research has been conducted with textbooks as the corpus (e.g., Gu, 2015; Shinabe, 2018; McCabe, 2004). In addition, these studies have not specifically focused on ESL/EFL textbooks. The studies which have focused specifically on ESL/EFL textbooks have analyzed them in line with different orientations and frameworks. For example, Marefat and Marzban (2014) and Amini and Birjandi (2012) studied gender in EFL textbooks, while Farzane, Kohandani, and Nejadansari (2014) and Zarei and Khalessi (2011) examined the EFL textbooks through the lens of culture. Azizifar, Koosha, and Lotfi (2010) also examined the textbooks with respect to their structure and content organization. To the authors' knowledge, no study has examined the content of ESL/ EFL textbooks for the extent of their compatibility with sustainability themes.

The other line of research was articles which attempted to study sustainability in educational settings. In one such study, Kolbe (2015) compared the knowledge and attitudes of students studying in two different schools namely a grammar school and a comprehensive school about waste management. Waste management is considered as a major environmental concern, and raising the next generation's awareness in this regard is of utmost importance. By means of a questionnaire, the data was obtained and analyzed both qualitatively and quantitatively. The results suggested that the students studying in the grammar school had a better understanding of waste management, were more aware of different methods of managing waste, and were also more likely to recycle waste themselves in the future. It was suggested to address the lack of knowledge among students of the comprehensive school. Both waste reduction and waste reuse were emphasized as being the most effective ways of dealing with waste. Therefore, raising the young generation's awareness can affect their future life style and make them citizens who value the themes of a sustainable life.

In another study, Bell (2016) criticized the present educational systems for not being totally compatible with sustainability values and emphasized the role a transformative pedagogy can have on training the next generation on being responsible towards our planet. The author suggests that by incorporating sustainability themes in educational programs, hopefully a sustainable economy will emerge globally as it has already emerged locally in some parts of the world. As Bell (2016, p. 55) puts it, "We need to prepare students not only for employment in a sustainable economy, but also with the skills and values that will allow them to live sustainable lifestyles on this planet."

In the field of English teaching, specifically in English for Specific Academic Purposes (ESAP), the need for a sustainable curriculum in teacher training programs was underscored in an article by Emadian, Gholami, and Sarkhosh (2018). Using a mixed-method design comprising quantitative and qualitative analyses, the authors conducted a needs analysis among two groups: a group of language instructors (n: 50) and a group of content specialists (n: 50) both teaching ESAP courses in various universities in Iran. In order to create a sustainable curriculum in line with needs of certain groups of learners (in this case English teachers and content specialist), it is crucial to consider what they need so as to consider it in the curriculum. Triangulation of the data was achieved by 
using three different tools of data collection, that is through structured interviews, observations and a questionnaire. The findings indicate that there are differences in the needs of the two groups with regard to professional, personal, and procedural areas. English instructors would rather be trained in the mentioned areas more than content specialists. They also had more difficulty in selecting the material for teaching in class. English instructors also were shown to be less interested in teaching due to their lower payments compared to content specialists. The findings also revealed that the relationship between the students and the content specialist was closer probably because their field of study is the same. The authors concluded that it is possible to create a sustainable curriculum which is compatible with needs and attitudes of each group which consequently can lead to more efficient pre-service and in-service teacher training programs.

Other studies which has to do more specifically with the present study are those concerning suitable sources as educational material that are in line with sustainability themes and values. Although the literature on this topic is rather scarce, three studies were approximately relevant. Believing that new material must be developed, Cary (2007), suggested using quotations from Antoine de Saint-Exupery's “The Little Prince" as proper vehicles to carry the message of sustainability to children. In fact, this has been done. Published as a brochure, the principles of the Earth Charter are stated "in the poetic and instructive style of a fairy tale" (Cary, 2007, p. 122). This reader-friendly brochure is widely used in Armenian schools. In the same vein, Ovsienko (2007), states that in the Republic of Tatarstan, in kindergarten and pre-school making children familiar with the values of sustainable life is possible with outdoor activities so that children can understand the importance of protecting the environment. Ovsienko (2007, p. 55) also explains the existing ways of using traditional sayings in Tatarstan and Russia as "an unobtrusive way of introducing important, and sometimes abstract, concepts in a flexible and interactive manner".

In a unique study, Cutanda and Murga-Menoyo (2014) attempted to examine the value of folklore and traditional stories of different peoples as sources for educational material for sustainable development. They examined 28 mythical and metaphorical texts that came from 19 cultures and 4 continents: Africa, Asia, America, and Oceania. As a framework, they constructed 23 categories of which 12 pertain to epistemological principles which were extracted after a thorough review of the literature on the model of education for sustainable development and complex-systems thinking and 11 outline the values and attitudes of sustainability for constructing which the Earth Charter was the main guideline. The results of a content analysis of the corpus revealed that the stories are totally in accordance with the principles of the Earth Charter. The authors believe that the potential of mythical and metaphorical stories of different peoples as educational material "is worth exploiting for improving the quality of education" (Cutanda \& Murga-Menoyo, 2014, p. 32). To the best of the author's knowledge, no other study has attempted to examine texts, whether educational or not, as to understand their coherence with the values of sustainability. The present study is an attempt to evaluate a series of EFL English textbooks to find out if such values and principles have been paid any attention to.

The objective of this study was to examine EFL textbooks to better understand whether their content is reflective of the values of sustainable development and to raise awareness of the importance of including such content in English language teaching textbooks used widely in Iranian EFL context. 


\section{Method}

\section{Corpora: English Language Teaching Textbooks}

The English series chosen to be examined in this study is Iran Language Institute (ILI) series for adults. This series was chosen because Iran Language Institutes is a language school with branches all over Iran. The languages taught are English, French, German, Arabic, Russian and Spanish. It is a well-known language school in Iran which is a trusted place for a lot of families to send their children and for all learners to receive a quality education. There are classes for children, teenagers, and adults. Therefore, the textbooks taught in the ILI can be influential in shaping a lot of English learners' mentalities. The series selected for the purpose of this study is for adults and include 18 books accompanied by workbooks ( 3 books for the basic level, 3 for the elementary level, 3 for pre-intermediate level, 3 for intermediate level, 3 for high intermediate level and 3 for advanced level). Each book is studied during a season-long semester and the whole program takes 18 semesters (4.5 years) in case repeating a semester is not needed. The main books are analyzed in terms of their content's compatibility with the principles of sustainability.

\section{Content Analysis Framework}

The framework for the content analysis in this study was constructed by considering two sources: The Earth Charter and The Roadmap for Implementing the Global Action Program on ESD. As was mentioned in the introduction, one of the documents the framework of analysis is based upon is the UNESCO Roadmap for Implementing the Global Action Program on ESD (2014, p. 11) based on which the highlighted areas of sustainable development include climate change, biodiversity, disaster risk reduction, and sustainable consumption and production.

The other document used as the foundation for building a framework of analysis is the Earth Charter (2000). The Earth Charter (2000, pp. 2-3) puts forward the following four principles: "The first one is respect and care for the community of life, the second is ecological integrity, the third social and economic justice and the last democracy, nonviolence, and peace".

Each principle is elaborated and is made clear though explanations. The concepts stated in the UNESCO Roadmap for Implementing the Global Action Program on ESD (2014) and the Earth Charter (2000) mostly overlap, therefore, the following fourteen selected areas were defined to summarize the major points of the two documents (Table 1 ).

Table 1

Sustainability-Related Themes

\begin{tabular}{ll}
\hline Themes & Explanation \\
\hline Life diversity & $\begin{array}{l}\text { Respecting all life forms and the interdependence of all } \\
\text { life forms, the harmony between animal life and human } \\
\text { life, the harmony between human and nature }\end{array}$ \\
$\begin{array}{ll}\text { Saving natural resources and } \\
\text { their mindful consumption }\end{array}$ & $\begin{array}{l}\text { Saving natural resources (e.g. petroleum, gas, minerals, } \\
\text { forests, rivers, etc.) }\end{array}$ \\
\hline
\end{tabular}


Sequel to Table 1.

Endangered species

Raising awareness about and Care for endangered species, hunting animals or fish in an uncontrolled way; preventing cruelty toward animals

\begin{tabular}{ll}
\hline Renewable energy resources & Using clean energy sources like the sun's or the wind's \\
\hline Pollution & $\begin{array}{l}\text { Raising awareness about pollution and the ways humans } \\
\text { are polluting the environment; ways of controlling pollution }\end{array}$ \\
\hline Recycling & Recycling waste and using recycled products \\
\hline Technology & $\begin{array}{l}\text { Mindful use of technology in ways that are not destructive } \\
\text { to the Earth, and the living things }\end{array}$ \\
\hline Poverty & $\begin{array}{l}\text { Raising awareness about poverty and how this phenomenon } \\
\text { affects peoples and the environment }\end{array}$ \\
\hline Discrimination & Fighting discrimination in all its forms \\
\hline Natural disasters & $\begin{array}{l}\text { Raising awareness about greenhouse effects and the changes } \\
\text { in climate due to human activities }\end{array}$ \\
\hline Collaborative problem solving \\
and peaceful life & $\begin{array}{l}\text { Knowing about natural disasters and their causes, con- } \\
\text { sequences and the role of humans in all that }\end{array}$ \\
$\begin{array}{l}\text { Knowing about collaborative problem solving, cooperation, } \\
\text { working with others and living peacefully with other people, } \\
\text { showing compassion and tolerating opposing ideas and } \\
\text { finding peaceful solutions for conflicts }\end{array}$ \\
\hline Cultures and spiritual practices & $\begin{array}{l}\text { Knowing about and respecting other peoples' ways of life, } \\
\text { cultural heritage, and spirituality }\end{array}$ \\
\hline Family & $\begin{array}{l}\text { Knowing about the value of family and paying attention to } \\
\text { the well-being of all its members }\end{array}$ \\
\hline
\end{tabular}

Table 1 was used as the basis of content analysis of the ILI English series to find out if these themes occured in the content and if so with what frequency. In each unit of the books, every part including conversations, passages, speaking and listening sections were examined. The unit of analysis for the passages was, following Cutanda and MurgaMenoyo's (2014) model, the paragraph. In cases when this was not possible like conversations, or speaking or listening activities where only the topic is specified, the whole activity in question was examined sentence by sentence. The recurring themes in a section were counted only once because especially when a text is long, there is a unifying general idea so it is quite natural for the themes to occur more than once. Having done the content analysis by the author, an experienced colleague who has taught all the books reviewed the results and a 100\% agreement on the results was achieved.

\section{Results and Discussion}

In the eighteen books that were evaluated, the sustainability themes were present. However, their distribution was not even. The themes were totally absent in some books and abundant in some others. The results of the content analysis are presented in Table 2. 


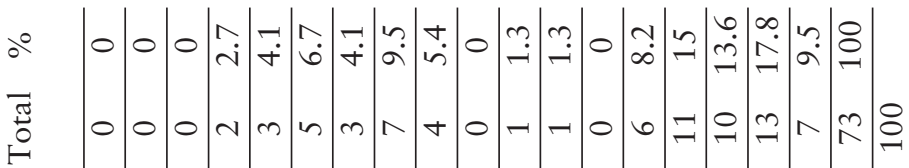

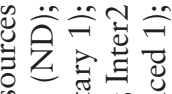
I

$\bar{\Xi}$

E $* *$

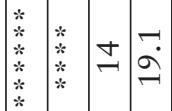

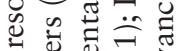

कo

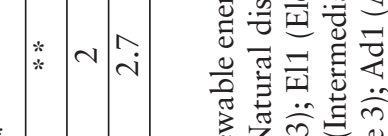

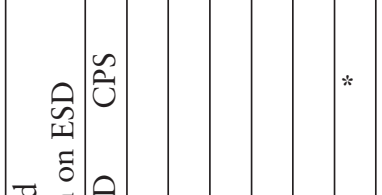

를 छ

苛

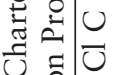

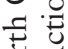

焉 专

$\cong \stackrel{0}{\circ}$

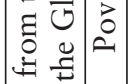

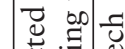

氖

㱐

$\cong$

政

范

की 20

क्ष०त

迁

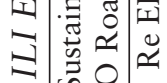

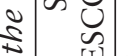

इ

ปับ

2

$\tau^{2}$

รี้

E

胥

난

$\frac{\sqrt[5]{2}}{\frac{5}{4}}$

है ह

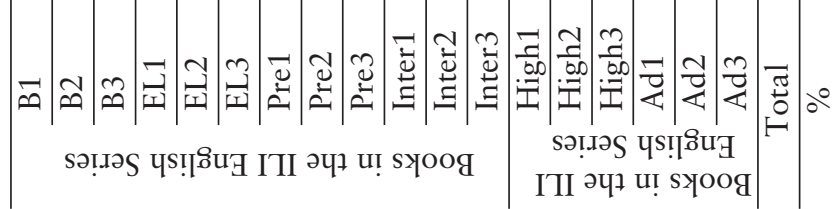

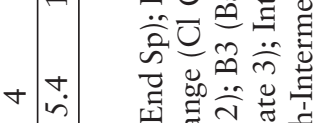

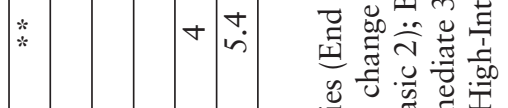

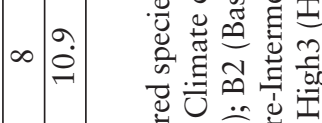

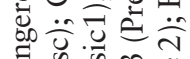

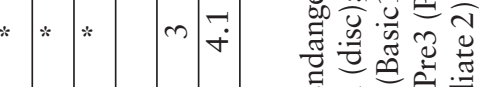

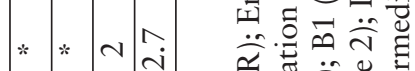

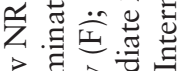

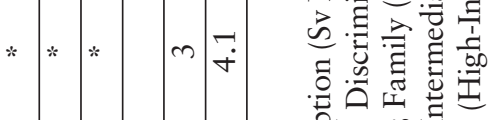

$* * \quad \ln \infty$

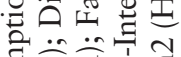

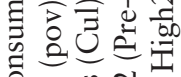

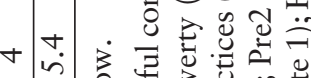

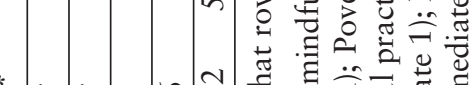

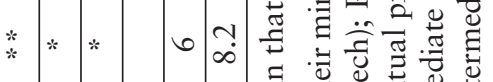

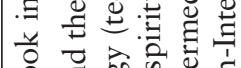

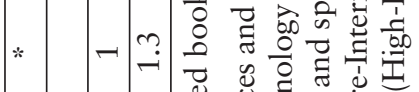

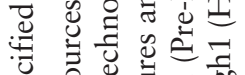

$\sqrt{n}$ की

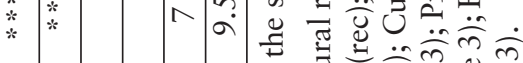

z

क

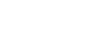


As it is evident from Table 2, there is a total absence of sustainability themes in B1, B2, B3, Inter1 and High1 books while some books like Ad2 enjoy having a large number of those themes. In all the 18 books, the themes and topics related to sustainability occurred 73 times. As was mentioned before, the distribution of the themes in the books is uneven. This becomes even more evident when we consider the number of chapters in each level. There are 10 units in Books for Basic, Elementary and High-Intermediate levels while there are 8 units in books for Pre-Intermediate and Intermediate levels. There are only 6 units in books for Advanced level. Each semester at the ILI lasts for 20 sessions regardless of the number of units in each book, therefore; when more sustainability themes occur in an Advanced book, it means that the learners have a greater chance of discussion, reading, listening or writing about them.

Among the themes, Cultures and Spiritual Practices have the greatest frequency of occurrence with 19.1\%. Renewable Energy Resources with 1.3 percent has occurred the least. Among the books, Advanced 2 enjoys the greatest frequency of sustainability themes with 17.8 percent of all the cases.

The distribution of the asterisks in the table reveals another pattern: The books for Elementary and Pre-Intermediate levels and the ones for High-Intermediate (2, 3) and Advanced levels have the greatest number of the themes in their content. Books for Basic levels, Intermediate levels and High-intermediate 1 have no or very few cases of sustainability themes in them. From a linguistic perspective, it might not be suitable to put sustainability themes in books for Basic levels as the vocabulary and the grammar needed to discuss such topics are way beyond what is presented in those books. However, it can be claimed that there is no need to have sustainability themes in length or elaborately in Basic levels. The mere introduction of such themes might even be enough for raising the awareness of the English learners. As Cutanda and Murga-Menoyo (2014) showed, stories can be great material for teaching sustainability. Simplified versions of stories from different peoples can not only convey the intended message but is an interesting way of making the learners familiar with other cultures so that they appreciate other ways of thinking. This in itself is one of the values of sustainability. Among the books that were examined, only two stories were found that promoted avoiding selfishness and greed and could indirectly teach the values pertaining to mindful consumption, sharing and saving resources. One of the stories was found in an elementary and the other in a high-intermediate book. Thus, it can be concluded that stories have the potential to be linguistically simple or complicated enough for all proficiency levels. In case of the two books for the Intermediate level (1 and 2) and one High-Intermediate (1), the lack of sustainability themes seems strange especially because they are present in the previous books (Pre-intermediate and Elementary). Table 2 also reveals that themes related to sustainability are more concentrated in the books for higher levels (e.g., High 3 or Advanced 2). Apparently, this is because learners' proficiency is good enough to discuss such issues without much difficulty. That might explain the high concentration of the themes in higher levels.

Another point worth discussing is the fact that in some books one or two themes are dominant (e.g., High 2, Advanced 2 and Advanced 3). This is due to the fact that a whole unit in the book is built around a certain theme. If you take High 2 as an example, a whole unit is devoted to natural disasters. The unit begins with a rather lengthy passage about hurricanes followed by exercises one of which includes another passage about hurricanes. Then, there is another passage about earthquakes with some exercises which 
is followed by a listening activity about extreme weather and a speaking activity the topic of which centers around natural disasters. All this is concentrated in a single unit out of the ten units which the book has. Throughout the book, there is only one other theme which is indirectly related to saving and sharing resources.

Considering the themes of sustainability, Culture, is the most frequent in the content of the books. The reason behind this might pertain to the nature of language learning. As was mentioned earlier in this paper, knowing about the culture of the people who speak a language is part of learning a language. However, in this English series, it was observed that instead of introducing the culture of English speaking countries, the culture of different people's, their traditions, and their spiritual ways have been emphasized. This is in line with the idea that EFL/ESL textbooks can be great vehicles for carrying such messages as respecting other people's ways of life, cultural heritage, and spirituality among other things. The following is an excerpt from Advanced 3 with the general theme of Culture:

Muslims believe God is nothing like anything we know or understand. God doesn't have a body or anything that can be seen or measured. God is not male or female (though God is called He in Islam). God was not born and will not die. God is outside time and space. God is simply beyond anything that humans can understand. Muslims believe that God is: the creator of the universe, the only god, eternal, all-powerful, all-knowing, all-seeing, allbearing, and all-willing.

In another group work speaking activity in the same unit people discuss their views:

Look at the following statements. Do you agree or disagree? Share your answers with the class and discuss your reasons.

a. Most people today don't have a coherent system of beliefs.

$b$. There is no contrast between believing in science and in religion at the same time.

c. There are all kinds of strange phenomenon in the universe which science can't explain.

d. There must be life on other planets.

e. We all need some kind of faith to help us get through.

$f$. Religion gives a special meaning to people's lives.

g. Religious beliefs give people a more positive outlook on their lives.

h. Believing in an afterlife can help people not to feel alone in the world.

$i$. Religious involvement is the most important source of satisfaction for all people.

$j$. There is a close link between altruistic behavior and faith.

This sort of activities can enhance the learners' knowledge about other viewpoints on religion and spirituality and might also lead to a more open and accepting attitude.

Almost all the other themes examined in this series are more or less present in the books. The two themes of Renewable Energy Sources and Discrimination, however, have occurred only once and twice respectively and only in Advanced books. These themes, along with the other two themes of Climate Change and Poverty with only three occurrences, could have received more attention as they are as important as the other topics of sustainability. 
It is worth noting that the textbook alone, however well-written, cannot achieve the educational goals its writers had in mind for it, whether language learning goals or ESD goals, without the active role of the teacher and the learners. Having a guiding role, teachers can pave the way for the better integration of the values and principles of a sustainable life with language learning. This can be very important when the book itself lacks the material partially or completely. As a teacher who has been teaching the ILI English series for adults for ten years, the author believes that in most cases the learners are willing and eager to discuss such matters with a minimum prompting from the teacher. For example, in Basic level, the books don't have content related to sustainability, however, there are activities about topics that can indirectly be related to sustainability (e.g. a conversation about going to the zoo, a warm-up activity about going camping, a listening activity about a flying doctor who works in Africa, a reading activity about a vacation in the forest, etc.). Although such activities might not be related to sustainability at first read, they can create a context to talk about some values in a simple, easy to understand way. The following reading passage is taken from Basic 3 book:

Dear Sam,

It's the last day of my vacation. On Monday, I was in the forest with my parents.

On Tuesday, Mom and I were on the ski slopes. The skiing was really good.

On Wednesday, we were in the hotel most of the time because it was so cold and snowy. I was hungry because the hotel food was not very good. On Thursday, dad and I were in the forest again. And today's Saturday. Time to say goodbye.

The above example (which is accompanied by a picture of a family in a forest) can create a good context for talking about forests, not littering it and saving trees. The teacher can have a facilitating role by asking questions from the class. For example, the teacher can ask where the forests in Iran are if it is OK to cut so many trees, and if it is OK to start a fire in the forest, etc. Thus, in Basic and Elementary levels, the teacher's role as an enhancer and facilitator for discussing the values of sustainability in class can be very important.

Teaching English and teaching the principles of a sustainable life can go hand in hand. The value of it lies in the great opportunity English learning classes provide for talking about such themes, raising learners' awareness about such issues and helping them come up with creative ways to contribute in solving the big environmental problems we face today. In essence, it is both the teachers and the learners who give meaning to any activity done in an English classroom. Textbooks will nevertheless have an orienting role. Without it, some of the principles of sustainability may never be brought into focus in a classroom.

\section{Conclusion}

The results of the present study contribute to our understanding of the presence of the values and principles of sustainability in an existing and already in-use EFL textbook series in Iran. As English textbooks have a great potential for integrating language learning and ESD, the findings of this study can help policymakers, educators, material developers, and English teachers to have a clearer picture of the existing content and to take steps toward improving it in line with the principles of sustainable lifestyle. Although 
the results endorse the presence of sustainability themes in ILI textbooks, they show that these themes are not distributed in all books evenly. In some cases, even in a single textbook, all the sustainability-related themes are concentrated in a single unit of the book.

The inclusion of legends and mythical stories (Cutanda \& Murga-Menoyo, 2014) in EFL/ESL textbooks, especially in Basic or Elementary levels, perhaps in a simplified way can also be a great improvement because such stories have been shown to have the values of sustainability inherent in them. Therefore, such tales will not only introduce cultural diversity and respect for other people's ways of thinking but will be a good source for introducing other sustainability-related themes as well. The role teachers play in organizing the lesson plan to integrate sustainability values whenever there is a chance must also be highlighted. Teacher training programs can prepare teachers and raise their awareness about these environmental issues and ESD so that they will have the necessary skills and knowledge to help learners internalize the principles of sustainability along with learning English. The framework used for the content analysis was created based on the principles of the Earth Charter and the UNESCO Roadmap for Implementing the Global Action Program on ESD. Although attempts were made to make the framework as inclusive as possible, future research in this area can improve and refine the framework. The present study was conducted to analyze the content of one English series that is taught inside Iran. This may limit the way the findings of this study can be generalized and used. Therefore, researchers interested in this field can consider analyzing internationally distributed English textbooks such as TouchStone, Top Notch, American English File, etc.

\section{References}

Amini, M., \& Birjandi, P. (2012). Gender bias in the Iranian high school EFL textbooks. English Language Teaching, 5(2), 134-147.

Azizifara, A., Kooshaa, M., \& Lotfi, A. (2010). An analytical evaluation of Iranian high school ELT textbooks from 1970 to the present. Procedia Social and Behavioral Sciences, 3, 36-44.

Bell, D. V. J. (2016). Twenty-first century education: Transformative education for sustainability and responsible citizenship. Journal of Teacher Education for Sustainability, 18(1). 48-56.

Cary, M. B. (2007). The Earth Charter as a pedagogical tool for sustainability at Yerevan State University, Armenia. In M. Vilela \& K. Corrigan (Eds.), Good practices using the Earth Charter (pp. 121-126). San José de Costa Rica: UNESCO/ECI.

Cutanda, G., \& Murga-Menoyo, M. (2014). Analysis of mythical-metaphorical narratives as a resource for education in the principles and values of sustainability. Journal of Teacher Education for Sustainability, 16(2), 18-38.

Emadian, F., Gholami, J., \& Sarkhosh, M. (2018). Towards a sustainable curriculum for ESAP teacher training programs: A profile of ESAP content specialists'vs. language instructors' needs. Journal of Teacher Education for Sustainability, 20(2), 139-157.

Gu, X. (2015) Evidentiality, subjectivity and ideology in the Japanese history textbook. Discourse \& Society, 26(1), 29-51. 
Hutchinson, T., \& Torres, E. (1999). The textbook as agent of change. ELT Journal, 48(4), 315-328.

Kolbe, K. D. (2015). Knowledge, attitudes and behavior regarding waste management in a grammar and a comprehensive school in England - results from a school questionnaire. Journal of Teacher Education for Sustainability, 17(1). 58-71.

Marefat, F., \& Marzban, S. (2014). Multimodal analysis of gender representation in ELT textbooks: Reader's perceptions. Procedia - Social and Behavioral Sciences, 98, 1093-1099.

McCabe, A. (2004). Mood and modality in Spanish and English history textbooks: The construction of authority. Text, 24, 1-29.

McDevitt, B. (2004). Negotiating the syllabus: A win-win syllabus. ELT Journal, 58(1), 3-9.

Nima Farzaneh, N., Kohandanib, M., \& Nejadansaric, D. (2014). A textbook evaluation of socio-cultural contexts in Top Notch series. Procedia-Social and Behavioral Sciences, 98, 472-481.

Ovsienko, L. V. (2007). Reorienting Tatarstanís educational system towards education for sustainability. In M. Vilela \& K. Corrigan (Eds.), Good practices using the Earth Charter (pp. 54-59). San José de Costa Rica: Unesco/ECI.

Rieckmann, M. (2018). Key themes in Education for Sustainable Development. In A. Leicht, J. Heiss, \& W. J. Byun (Eds.), Issues and trends in Education for Sustainable Development (pp. 61-85). Paris: UNESCO.

Shinabe, N. (2018). Revealing a hidden curriculum in educational discourses: A study of the representation of Europe and Asia in Spanish and Japanese school textbooks. Discourse \& Society, 29(6), 674-690.

The Earth Charter (2000). The Earth Charter in action 2000 annual report. Retrieved from http://earthcharter.org/virtual-library2/the-earth-charter-in-action-2000annual-report/

UNESCO (2012). From green economies to green societies: UNESCO's commitment to sustainable development. Paris: UNESCO.

UNESCO (2014). UNESCO Roadmap for Implementing the Global Action Programme on Education for Sustainable Development. Paris: UNESCO. Retrieved from http://unesdoc.unesco.org/images/0023/002305/230514e.pdf

Zarei, G., \& Khalessib, M. (2011). Cultural load in English language textbooks: An analysis of interchange series. Procedia Social and Behavioral Sciences, 15, 294301.

Correspondence concerning this paper should be addressed to Zhila Mohammadnia, Assistant Professor of Applied Linguistics, English language Department, Urmia University 165, Urmia, Iran. Email: z.mohammadnia@urmia.ac.ir 